\title{
PERSISTENCE OF THE FCETAL TYPE OF PULMONARY ARTERY STRUCTURE IN THE SINUS VENOSUS DEFECT
}

\author{
BY
}

\author{
T. C. WILLIAMS
}

\section{From the Department of Pathology, The Children's Hospital, Birmingham}

In patients with atrial septal defect who have normal pulmonary artery pressures, it is thought that the development of the left-to-right shunt after birth has been gradual, so that the pulmonary arteries have been allowed to undergo the changes that normally occur during infancy. In those with significant pulmonary hypertension, these structural changes are thought to have been incomplete (Wood, 1958; Besterman, 1961).

Patients with the sinus venosus defect may have a large pulmonary blood flow without pulmonary hypertension (Swan et al., 1957). The incidence of significant pulmonary hypertension, however, is appreciably greater than with isolated atrial septal defect (Burchell, 1959; Besterman, 1961). In the case to be described, the elastic configuration of the pulmonary trunk indicated (Heath et al., 1959) that pulmonary hypertension persisted from birth.

It seems that among patients with the sinus venosus defect the reaction of the pulmonary arteries after birth may vary between transition to the normal adult type of structure, and persistence, as in this case, of the fotal structure: yet the anatomy of the malformation is fairly constant. This patient provided the opportunity to examine whether this variability reflects such anatomical differences as do occur.

\section{Case History}

The boy was a first child, born at term on April 9, 1958, weighing $5 \mathrm{lb} .12 \mathrm{oz}$. (2607 g.). His mother suffered toxæmia during the final six weeks of pregnancy. Fœtal distress during labour necessitated cæsarean section, and the liquor was seen to be meconium-stained. For the first week he seemed normal. On the tenth day he developed œdema of his feet, but at 1 month he was again apparently normal, remaining so until he was nearly 18 months of age.

He was first seen in this hospital in December 1959, when he was said to have been more easily tired, less contented, and perhaps a little short of breath, for three months: he vomited occasionally and was restless at night. He was underweight $(18 \mathrm{lb} .6 \mathrm{oz} .(8 \cdot 3 \mathrm{~kg}$.)), dyspnœic, mildly cyanosed, and in congestive heart failure. The blood pressure was $125 / 50 \mathrm{~mm}$. Hg. The heart was large, with a tapping apical impulse. The pulmonary second sound was split, and there was a loud systolic murmur which was maximal to the left of the sternum over the second intercostal space.

Fluoroscopy showed a large heart, with prominence of the right atrium and pulmonary artery, and pulmonary vascular congestion. Venous cineangiocardiography from the right elbow showed an early rightto-left shunt at atrial level (Fig. 1); in the later stages there was evidence of a large left-to-right flow. The electrocardiogram indicated a large right atrium and right ventricle, and suggested the presence of pulmonary hypertension. Cardiac catheterization from the right groin was carried out on January 20, 1960 From the right atrium (pressure $5 \mathrm{~mm}$. $\mathrm{Hg}$ ), a right pulmonary vein was entered (pressure $6 \mathrm{~mm} . \mathrm{Hg}$ ) and also a left superior vena cava. The pulmonary artery pressure was $45 / 20 \mathrm{~mm}$. $\mathrm{Hg}$. The oxygen saturation in the left atrium was 85 per cent; high in the right atrium it was 82 per cent, and in the pulmonary artery it was 67.5 per cent. Total pulmonary resistance was estimated (Lucas et al., 1961) to be about 660 dyne sec. $/ \mathrm{cm}^{-5}$. 
Fig. 1.-Venous cineangiocardiogram in left anterior oblique position. Tracing from an early frame showing the beginning of the right and left atrial opacities.

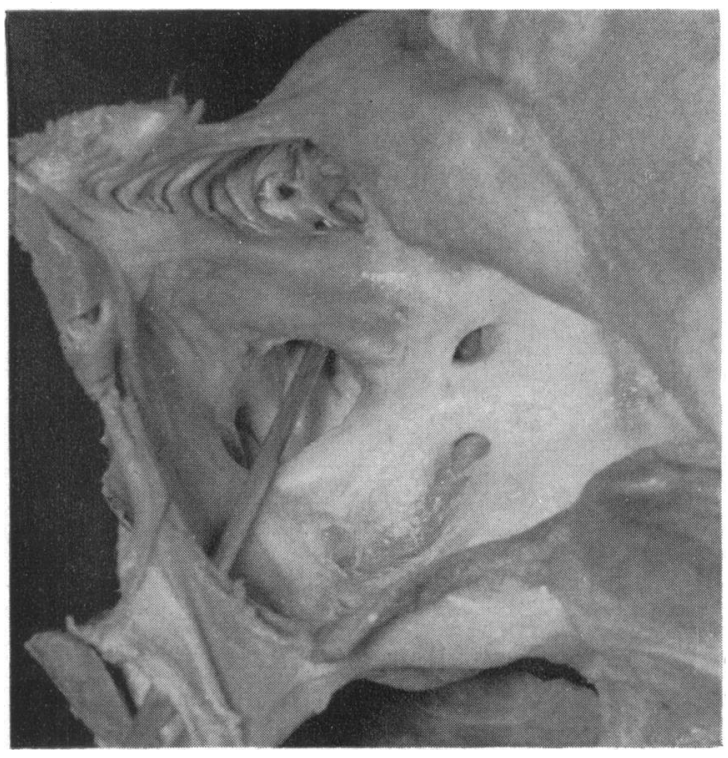

FIG. 2.-Photograph showing the interior of the right atrium and the high interatrial communication. The probe passes from the inferior vena cava into the superior vena cava. Another probe, passing from the left atrium into the right middle pulmonary vein, has drawn the orifice of this vein slightly to the left of its true position.

Following his admission into hospital, his condition, which was thought to have been aggravated by a respiratory infection, improved on digoxin, chlorothiazide, and antibiotics. After his discharge he was maintained on digoxin and antibiotics, but he suffered from repeated respiratory infections. At the age of 2 years he weighed $18 \mathrm{lb} .8 \mathrm{oz} .(8.5 \mathrm{~kg}$.) Cyanosis was sometimes noted, but there was no clubbing. He was readmitted for corrective surgery, but died on October 5, 1960, seven hours after a preparatory tracheostomy.

Post-mortem Findings. No primary disease was found outside the cardiovascular system. The heart $(180 \mathrm{~g}$.) was three times the normal weight. The right ventricle was huge, being both hypertrophied and dilated. The right atrium was also hypertrophied and dilated. The left atrium was moderately enlarged. The left ventricle, which appeared normal in size, was flattened against the bulging interventricular septum.

A persistent left superior vena cava drained into the very large coronary sinus. The right superior vena cava entered the heart in the plane of the interatrial septum, immediately above a rounded anomalous interatrial communication $(1.1 \mathrm{~cm}$. in diameter) which was situated postero-superiorly, $0.7 \mathrm{~cm}$. above the superior margin of the fossa ovalis (Fig. 2). There was narrow, oblique patency of the foramen ovale $(0.25 \mathrm{~cm}$. in diameter and $0.75 \mathrm{~cm}$. in length).

The endocardium was moderately thickened throughout the atria, mostly normal in the right ventricle, and entirely normal in the left ventricle. The valve orifices had the following measurements in circumference: tricuspid $9.3 \mathrm{~cm}$.; pulmonary $6.0 \mathrm{~cm}$.; mitral $4.8 \mathrm{~cm}$.; aortic $3.5 \mathrm{~cm}$. The cusps of all the valves, except the aortic, were moderately thickened, principally along their contact margins. The ductus arteriosus was ligamentous.

The left pulmonary veins joined the left atrium normally. The connexions of the right pulmonary veins, however, were all to some extent anomalous (Fig. 3). A very small subsidiary vein $(0 \cdot 15 \mathrm{~cm}$. in internal circumference) descended from the apical region of the right upper lobe, and entered the right superior vena cava just below the azygos vein. Two veins joined to form the main right superior vein, which entered the right superior vena cava $0.7 \mathrm{~cm}$. above its termination. The middle vein connected with the atria opposite the anomalous interatrial communication, slightly to the right of the plane of the interatrial septum. The main right inferior vein, and a lesser vein which drained the apical part of the right lower lobe, terminated together, also in the region of the anomalous interatrial communication but to the left of the plane of the 


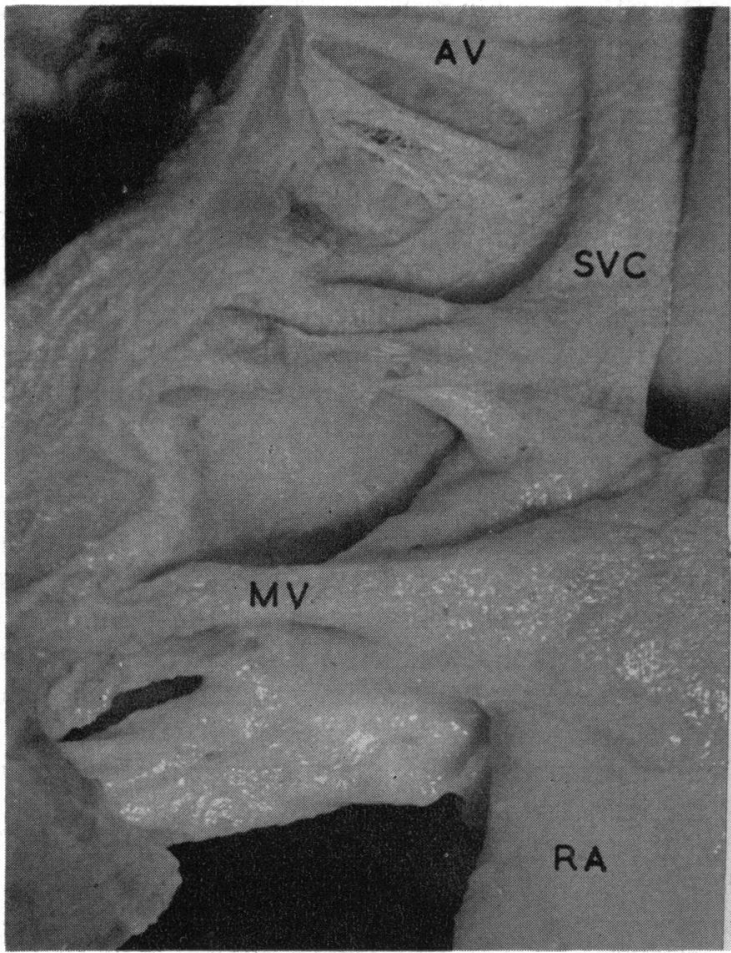

FIG. 3.-The anomalous right pulmonary veins. The small vein from the apical region of the right upper lobe lies just below the azygos vein (AV). The middle vein (MV) partly overlies the vein draining the upper part of the right lower lobe.

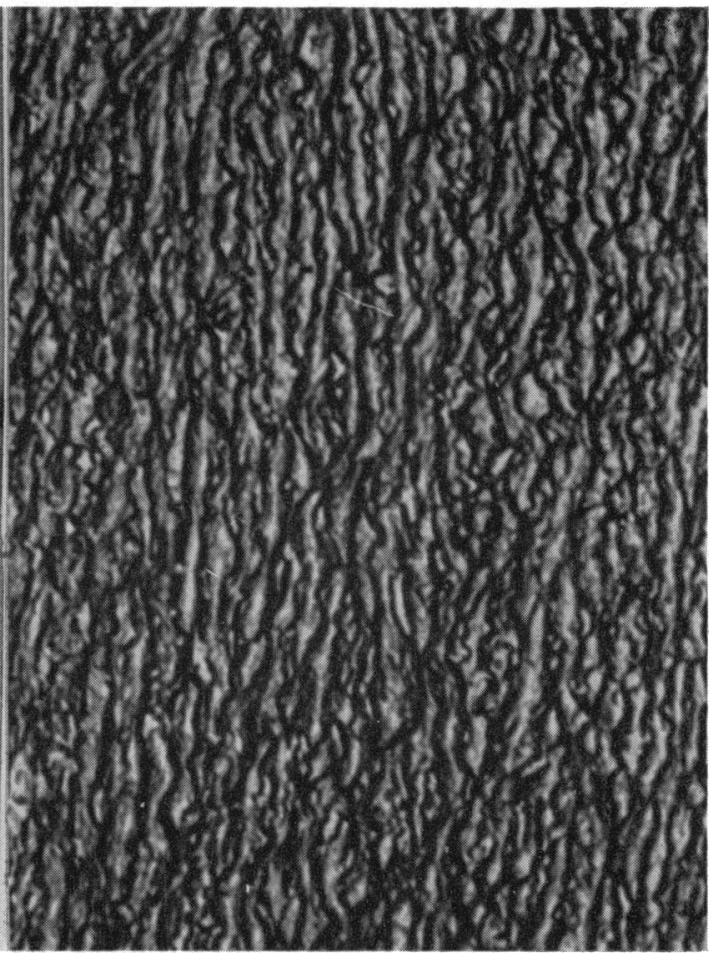

FIG. 4.-Part of a transverse section of the pulmonary trunk, showing the aorta-like arrangement of the elastic tissue. (Weigert's elastic. $\times 78$.)

interatrial septum. Apart from the small vein from the apex of the right upper lobe, the right pulmonary veins were comparable, in internal circumference, with those from the left lung.

Histology. The elastic configuration of the pulmonary trunk was aortic in type (Fig. 4). There was severe hypertensive pulmonary vascular disease, with fibrinoid necrosis and the formation of dilatation lesions.

\section{Discussion}

In the sinus venosus defect, an anomalous interatrial communication that is situated posterosuperiorly, immediately below the orifice of the superior vena cava, is associated with anomalous connexion of right pulmonary veins. The sex incidence noted among recorded cases shows a male preponderance ( 36 males : 23 females).

The right pulmonary veins may show variation in their anatomy (Brock and Ross, 1959). In their mode of connexion, however, they present a fairly uniform pattern according to Bedford and Sellors (1960), the superior vein opening into the superior vena cava, and the middle vein into the right or both atria at the level of the interatrial communication, while the inferior vein connects normally.

The interatrial communication is characteristically rather small. In young patients, Brock and Ross (1959) described it as being about 1.5 to $1.75 \mathrm{~cm}$. wide, and measurements given by Evans, Rowe, and Keith (1961) are comparable. Measurements given by Swan et al. (1957), presumably from adults, are generally larger; but in the patient with the severest degree of pulmonary hypertension, the communication measured only $1.0 \times 0.5 \mathrm{~cm}$. In a man surviving to the age of 67 years (Atkinson et al., 1940), it was about $2.0 \times 3.0 \mathrm{~cm}$. in diameter. 
Of associated features, patency of the foramen ovale is common, and persistence of the left superior vena cava is not uncommon. Occasionally there is a true fossa ovalis defect. Lewis et al. (1955) illustrated what they considered to be a confluent fossa ovalis and sinus venosus defect, but the superior vena cava is shown to enter the heart, uncharacteristically, slightly to the right of the plane of the interatrial septum.

Persistence of the left superior vena cava distinguished the present case of sinus venosus defect from the majority. The interatrial communication was smaller than most, while the interatrial septum below it was virtually intact. The pattern of anomalous pulmonary venous connexion differed in one respect from that described by Bedford and Sellors (1960), since the orifice of the right inferior veins was abnormally high, being $2.5 \mathrm{~cm}$. from the orifice of the inferior vena cava, but only $0.7 \mathrm{~cm}$. from that of the right superior vena cava: in normal hearts it has been observed to lie about midway between these orifices. All the right pulmonary veins connected above the level of the free upper margin of the interatrial septum.

These differences probably affected the intracardiac circulation before birth. After birth, the smaller the interatrial communication, the more likely it is that the blood returned to the right atrium by the anomalous pulmonary veins would pass into the pulmonary circulation, tending to maintain the pulmonary artery pressure and to delay the so-called involution of the pulmonary arteries. In this patient, the venous return to the right atrium after birth may have been greater than is usual with the sinus venosus defect, not only because the pulmonary venous anomaly was possibly more extensive, but also because of the persistence of the left superior vena cava.

Apart from these anatomical considerations, fœtal distress during labour, assuming it resulted in collapse and consolidation within the lungs, was the only obvious incident in the patient's early history that may have contributed to the persistence of pulmonary hypertension from birth.

\section{Summary}

The case is described of a boy with the sinus venosus defect, who died with severe hypertensive pulmonary vascular disease at the age of $2 \frac{1}{2}$ years. Histology showed that the pulmonary trunk retained the fœtal type of elastic tissue configuration. The anatomy of the defect is reviewed so as to display the differences that possibly accounted for the persistence of pulmonary hypertension from birth.

I wish to thank Dr. O. H. Wolff, Dr. Clifford Parsons, and Mr. K. D. Roberts for permission to publish this case. The tracing from the cineangiocardiogram (Fig. 1) was kindly provided by Dr. Roy Astley.

\section{References}

Atkinson, W. J., Dean, J. L., Kennerdell, E. H., and Lambertsen, C. J. (1940). A multiple anomaly of the human heart and pulmonary veins. Anat. Rec., 78, 383.

Bedford, D. E., and Sellors, T. H. (1960). In Modern Trends in Cardiology, ed. A. Morgan Jones, p. 138. Butterworths, London.

Besterman, E. (1961). Atrial septal defect with pulmonary hypertension. Brit. Heart J., 23, 587.

Brock, R., and Ross, D. N. (1959). The sinus venosus type of atrial septal defect. Surgical treatment. Guy's Hosp. Rep., 108, 291.

Burchell, H. B. (1959). Studies in pulmonary hypertension in congenital heart disease. Brit. Heart J., $21,255$.

Evans, J. R., Rowe, R. D., and Keith, J. D. (1961). The clinical diagnosis of atrial septal defect in children. Amer. J. Med., 30, 345.

Heath, D., Wood, E. H., DuShane, J. W., and Edwards, J. E. (1959). The structure of the pulmonary trunk at different ages and in cases of pulmonary hypertension and pulmonary stenosis. J. Path. Bact., 77, 443.

Lewis, F. J., Taufic, M., Varco, R. L., and Niazi, S. (1955). The surgical anatomy of atrial septal defects: experiences with repair under direct vision. Ann. Surg., 142, 401.

Lucas, R. V., St. Geme, J. W., Anderson, R. C., Adams, P., and Ferguson, D. J. (1961). Maturation of the pulmonary vascular bed. Amer. J. Dis. Child., 101, 467.

Swan, H. J. C., Kirklin, J. W., Becu, L. M., and Wood, E. H. (1957). Anomalous connection of right pulmonary veins to superior vena cava with interatrial communications. Hemodynamic data in eight cases. Circulation, 16, 54.

Wood, P. (1958). The Eisenmenger syndrome; or pulmonary hypertension with reversed central shunt. Brit. med. J., 2,755 . 